\title{
Influence of Humidity on Voids Formation Inside the Solder Joint
}

\author{
Karel Dušek ${ }^{1, *}$, Jan Vlach ${ }^{1}$, Michal Brejcha ${ }^{1}$, Lenka Hájková1, \\ Pavel Žák ${ }^{1}$, and Ladislav Pospíšil ${ }^{2}$ \\ ${ }^{1}$ Faculty of Electrical Engineering, Department of Electrotechnology, Czech Technical University in Prague, \\ Technická 2, Prague 6, 166 27, Czech Republic \\ ${ }^{2}$ Faculty of Electrical Engineering, Development and Implementation Laboratories, Czech Technical \\ University in Prague, Technická 2, Prague 6, 166 27, Czech Republic
}

Void is defined such as blow hole in the solder joint. Voids may degrade the mechanical and conductive properties of the solder joint and thus decrease the reliability. Article deals with influence of humidity on voids formation inside the solder joint structure. Experimental part was carried on testing samples, where we used three types of solder pastes (Sn62Pb36Ag2, Sn96.5Ag3Cu0.5 and Sn95.5Ag4Cu0.5), three types of reflow technology (hot air, vapor phase and infra radiation reflow technology) and three types of humidity environments. The inspection was made on X-ray and following diagnostic was made by image analysis with special software. We evaluate the number of voids together with their total area of all voids inside solder joints. Results indicate that the number of voids together with their total area mainly depends on type of used solder paste. Dependence of used reflow process on voids formation is minor and the influence of components humidity on voids formation wasn't observed.

KEYWORDS: Solder Joint, Humidity, Voids.

\section{INTRODUCTION}

One of the most important factors on reliability of electronics assembly is reliable solder joints. Reliability of solder joints can be decreased by the voids formation. Void is defined such as blow hole inside the solder joint. Voids may degrade the mechanical and conductive properties of the solder joint and thus decrease the reliability and lifetime of the product. ${ }^{1}$ The effect of voids on the reliability depends on frequency, size and on location inside the solder joint.

We can classify voids into two basic categories-micro and macro voids. Micro voids exists in many forms, each form has different mechanism of void creation. Due to their very small diameters they are hard to detect during X-ray inspection. As example of micro voids let's mention the planar micro voids. Planar micro voids are smaller than 25-50 $\mu \mathrm{m}$ in diameter. They appear on the interface between the solder joint and solder pad, above the intermetallic layer. ${ }^{2}$ Example of planar micro void is in Figure 1 can leads to failure.

Macro voids are the large sized voids, which we can commonly see during X-ray inspection. Diameter of macro

\footnotetext{
*Author to whom correspondence should be addressed.

Email: dusekk1@fel.cvut.cz

Received: 17 July 2012

Accepted: 10 September 2012
}

voids can be up to $300 \mu \mathrm{m}$. They can be found anywhere inside the solder joint. Example of 3D CT reconstruction from X-ray images of macro voids in BGA component is in Figure 2. Existing standards specify the amount of voids inside the solder joints (for BGA package specify the amount of voids less than $25 \%$ of solder joint volume).

Macro voids are caused by the amount of outgassing flux that gets entrapped in the solder joint during reflow. ${ }^{2,3}$ The outgassing substance is generally produced by the evaporation of the solvent in the solder paste and the rheological additives in the solder paste that may evaporate in the heating process during reflow. ${ }^{4}$ The outgassing substance may also be generated by the metallization of the substrate, component or the solder powder surface during the fluxing reaction in the reflow process. Previous studies have indicated that the reflow process and the solder material are the most significant factors that affect void formation. ${ }^{5}$ Due to lower reliability of the product the searching of influences on voids formation inside the solder joints is very important.

\section{EXPERIMENTAL PART}

Experimental part was carried on testing samples, where we used three types of solder pastes (Sn62Pb36Ag2, 


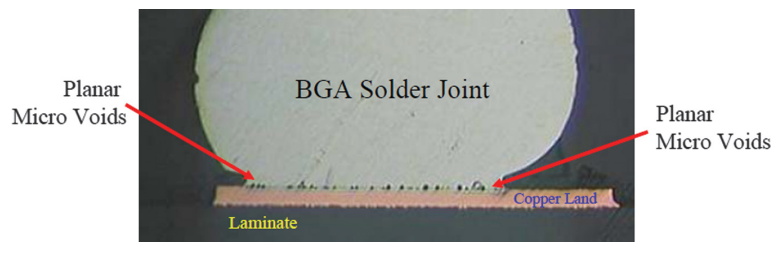

Fig. 1. Example of a planar micro void. ${ }^{2}$



Fig. 2. Example of 3D X-ray inspection of macro voids inside the solder joints of BGA.

Table I. Specification of solder pastes which was used in experiment.

\begin{tabular}{lccc}
\hline $\begin{array}{l}\text { Type of } \\
\text { solder paste }\end{array}$ & Sn62Pb36Ag2 & Sn96.5Ag3Cu0.5 & Sn95.5Ag4Cu0.5 \\
\hline Grain size $[\mu \mathrm{m}]$ & $20-50$ & $25-45$ & $25-45$ \\
Flux & RMA & ROL0 & REL1 \\
Flux content $[\%]$ & 13 & 11.5 & 10.88 \\
Melting & 179 & 217 & 217 \\
$\quad$ temperature $\left[{ }^{\circ} \mathrm{C}\right]$ & & & \\
\hline
\end{tabular}

Sn96.5Ag3Cu0.5 and Sn95.5Ag4Cu0.5-closer specification of solder pastes is in Table I), three types of reflow technology (hot air-HA, vapor phase-VP and infra radiation-IR) and three types of humidity environments.

At the beginning of the experiment the PCB together with SMD resistors (type 1206), were placed in three different types of humidity environments (dry-humidity was less than 5\%, ambient - average humidity was around $60 \%$ and humid environment $-100 \%$ humidity) for 500 hours. After that we took the PCB together with SMD components from environments and we prepared samplesthe solder paste was applied on the solder pads using a screen printing process (volume of solder paste is given by the printing template and it was same for all used solder pastes), components were placed on PCB and then the solder paste was reflowed.

We have measured temperature profiles for each reflow technology before reflow process. Temperature profile for hot air furnace is in Figure 3, for vapor phase soldering is in Figure 4 and for infra radiation reflow technology is in Figure 5. After the reflow process we made inspection of voids inside the solder joints.

The inspection was made on X-ray and following diagnostic was made by image analysis with special software. Example of the captured image of prepared sample on $\mathrm{X}$-ray is in Figure 6. We evaluate the number of voids together with their total surface area of all voids inside solder joints. Measured results are in Table II.



Fig. 3. Temperature profile for hot air furnace.

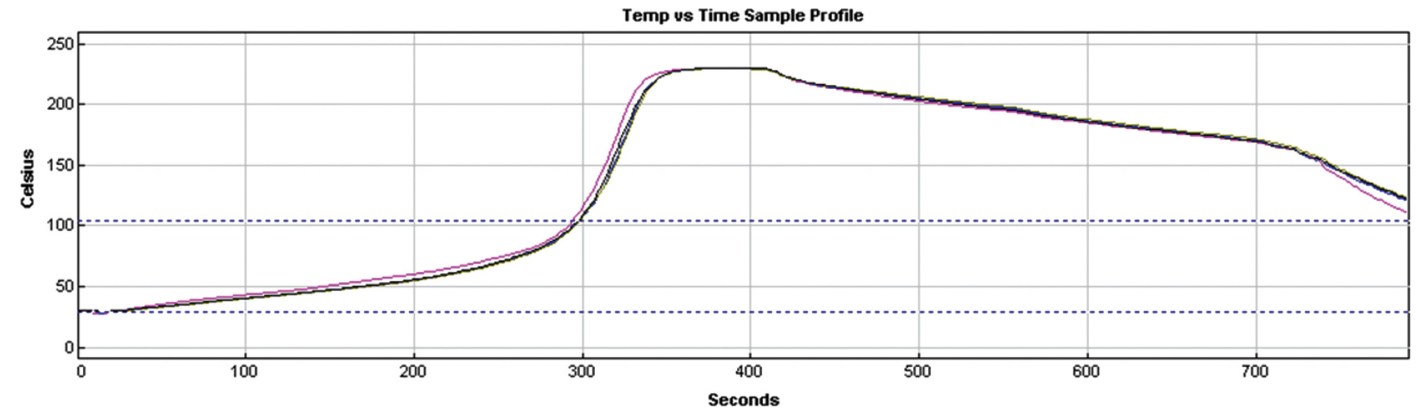

Fig. 4. Temperature profile for vapor phase soldering. 


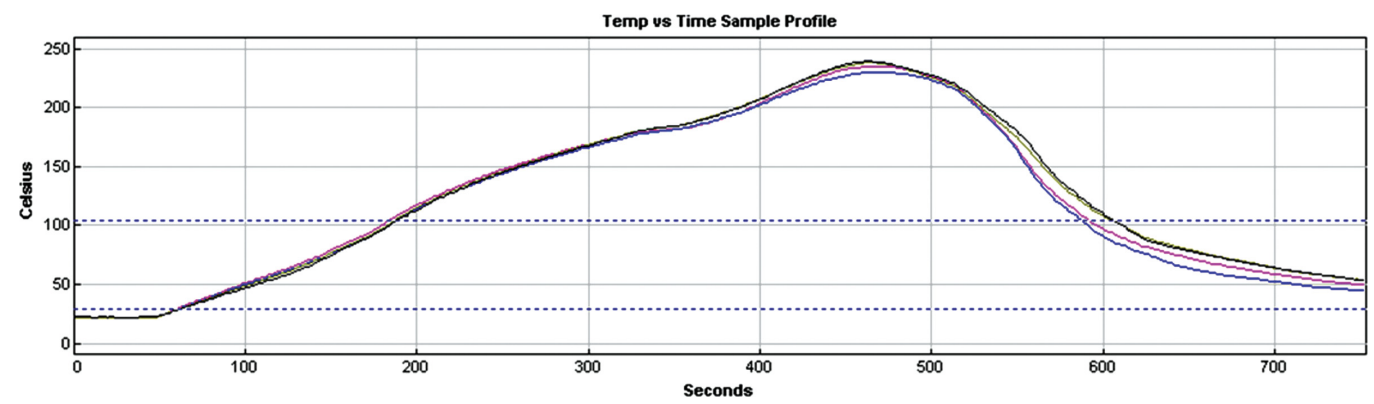

Fig. 5. Temperature profile for infra radiation soldering.

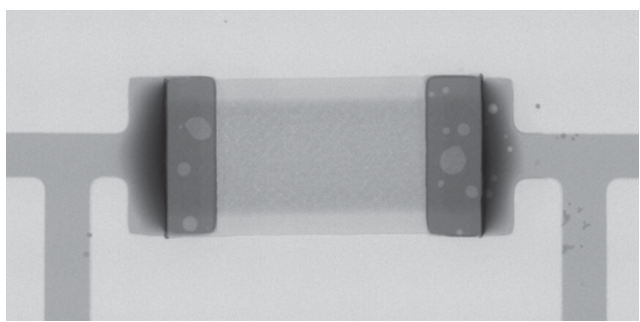

Fig. 6. Example of the captured image of prepared sample on X-ray.

\section{RESULTS}

On such prepared samples we examined influence of humidity, used reflow process and used solder paste on the voids formation. We evaluated 28 solder joints
(14 SMD components) for each combination (type of environment, type of solder paste and type of reflow technology).

Influence of humidity on the voids formation-results are shown in Figure 7 (number of voids) and in Figure 8 (total surface area of voids). After the closer examination we can say, that there is no influence of humidity on the voids formation in case of Sn62Pb36Ag2 and $\mathrm{Sn} 96.5 \mathrm{Ag} 3 \mathrm{Cu} 0.5$ solder pastes. The influence of humidity on voids formation appeared in case of $\mathrm{Sn} 95.5 \mathrm{Ag} 4 \mathrm{Cu} 0.5$ solder paste, which was reflowed by infra radiation. We can conclude, that we can't confirm clear correlation between humidity and voids formation.

Influence of reflow process on the voids formationresults are shown in Figure 9 (number of voids) and in

Table II. Number of voids and total surface area of all voids inside 28 solder joints.

\begin{tabular}{|c|c|c|c|c|c|}
\hline Environment & Reflow technology & Solder paste & $\begin{array}{l}\text { Number of } \\
\text { voids [pc] }\end{array}$ & $\begin{array}{c}\text { Total voids } \\
\text { surface area }\left[\mathrm{px}^{2}\right]\end{array}$ & $\begin{array}{c}\text { Total voids } \\
\text { surface area }\left[\mu \mathrm{m}^{2}\right]\end{array}$ \\
\hline \multirow[t]{9}{*}{ Dry } & \multirow[t]{3}{*}{ HA } & $\mathrm{Sn62Pb36Ag2}$ & 301 & 23605 & 1049111,11 \\
\hline & & Sn96.5Ag3Cu0.5 & 309 & 68788 & 3057244,44 \\
\hline & & $\mathrm{Sn} 95.5 \mathrm{Ag} 4 \mathrm{Cu} 0.5$ & 824 & 71149 & 3162177,78 \\
\hline & \multirow[t]{3}{*}{ IR } & $\mathrm{Sn62Pb36Ag2}$ & 577 & 41364 & 1838400,00 \\
\hline & & Sn96.5Ag3Cu0.5 & 298 & 56189 & 2497288,89 \\
\hline & & Sn95.5Ag4Cu0.5 & 631 & 73904 & 3284622,22 \\
\hline & \multirow[t]{3}{*}{ VP } & $\mathrm{Sn62Pb36Ag2}$ & 799 & 37511 & 1667155,56 \\
\hline & & $\mathrm{Sn} 96.5 \mathrm{Ag} 3 \mathrm{Cu} 0.5$ & 323 & 61971 & 2754266,67 \\
\hline & & Sn95.5Ag4Cu0.5 & 855 & 81304 & 3613511,11 \\
\hline \multirow[t]{9}{*}{ Normal } & \multirow[t]{3}{*}{ HA } & $\mathrm{Sn62Pb36Ag2}$ & 424 & 31157 & 1384755,56 \\
\hline & & Sn96.5Ag3Cu0.5 & 367 & 70016 & 3111822,22 \\
\hline & & Sn95.5Ag4Cu0.5 & 770 & 89641 & 3984044,44 \\
\hline & \multirow[t]{3}{*}{ IR } & $\mathrm{Sn} 62 \mathrm{~Pb} 36 \mathrm{Ag} 2$ & 854 & 43273 & 1923244,44 \\
\hline & & Sn96.5Ag3Cu0.5 & 270 & 46837 & 2081644,44 \\
\hline & & Sn95.5Ag4Cu0.5 & 733 & 101537 & 4512755,56 \\
\hline & \multirow[t]{3}{*}{ VP } & $\mathrm{Sn} 62 \mathrm{~Pb} 36 \mathrm{Ag} 2$ & 688 & 35620 & 1583111,11 \\
\hline & & Sn96.5Ag3Cu0.5 & 263 & 53082 & 2359200,00 \\
\hline & & Sn95.5Ag4Cu0.5 & 738 & 115001 & 5111155,56 \\
\hline \multirow[t]{9}{*}{ Humid } & \multirow[t]{3}{*}{ HA } & $\mathrm{Sn} 62 \mathrm{~Pb} 36 \mathrm{Ag} 2$ & 391 & 30675 & 1363333,33 \\
\hline & & Sn96.5Ag3Cu0.5 & 352 & 57953 & 2575688,89 \\
\hline & & $\mathrm{Sn} 95.5 \mathrm{Ag} 4 \mathrm{Cu} 0.5$ & 606 & 70811 & 3147155,56 \\
\hline & \multirow[t]{3}{*}{ IR } & Sn62Pb36Ag2 & 486 & 44134 & 1961511,11 \\
\hline & & Sn96.5Ag3Cu0.5 & 359 & 55335 & 2459333,33 \\
\hline & & Sn95.5Ag4Cu0.5 & 1107 & 122256 & 5433600,00 \\
\hline & \multirow[t]{3}{*}{ VP } & $\mathrm{Sn62Pb36Ag2}$ & 653 & 36249 & 1611066,67 \\
\hline & & Sn96.5Ag3Cu0.5 & 366 & 71564 & 3180622,22 \\
\hline & & Sn95.5Ag4Cu0.5 & 827 & 90964 & 4042844,44 \\
\hline
\end{tabular}




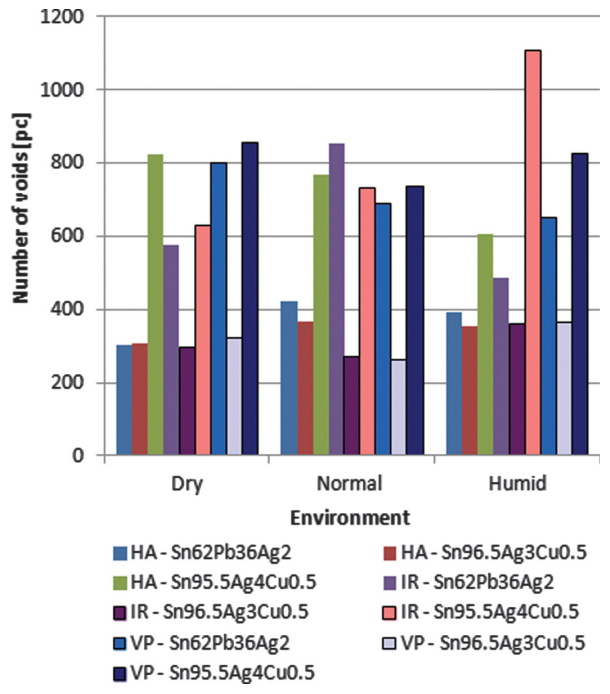

Fig. 7. Influence of humidity on number of voids.

Figure 10 (total surface area of voids). After the closer examination we can say, that there is no influence of reflow process on the voids formation in case of $\mathrm{Sn} 96.5 \mathrm{Ag} 3 \mathrm{Cu} 0.5$ solder paste. The solder paste Sn62Pb36Ag2 has best results (lowest voids formation) in case of hot air reflow technology. The worst result (the highest voids formation) has $\mathrm{Sn} 95.5 \mathrm{Ag} 4 \mathrm{Cu} 0.5$ solder paste in case of infra radiation and vapor phase reflow technology. When we would like to confirm the influence of reflow process on the voids formation, we have to take in consideration temperature profiles for each reflow technology. The temperature profiles for each reflow technology are little bit different, especially in part of flux activation. Even so, it seems that the influence of used reflow process on voids formation is minor.

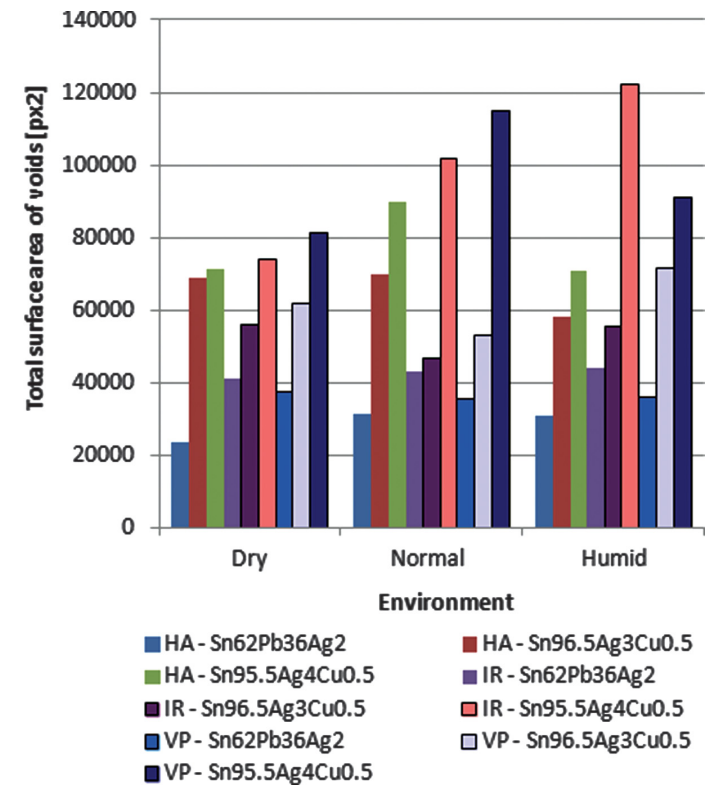

Fig. 8. Influence of humidity on total surface area of voids.

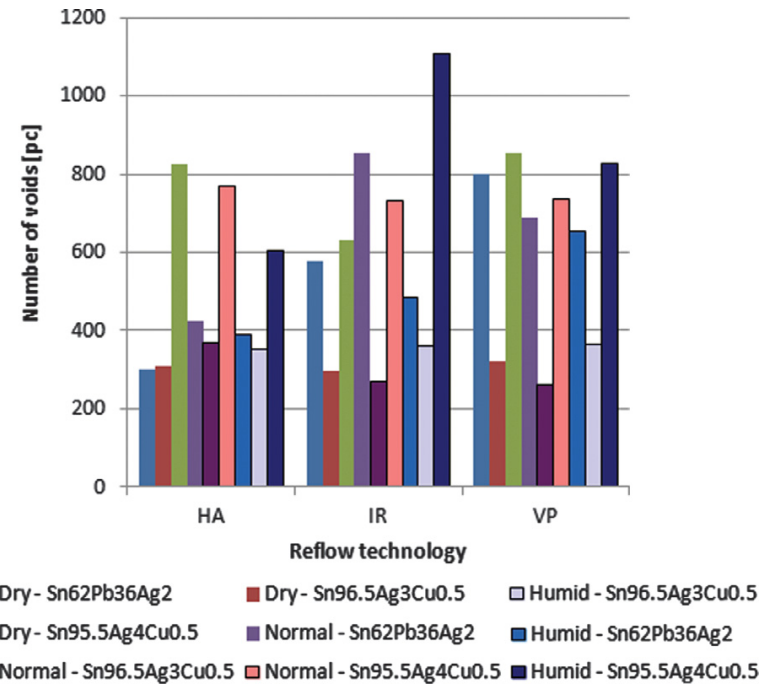

Fig. 9. Influence of reflow process on number of voids.

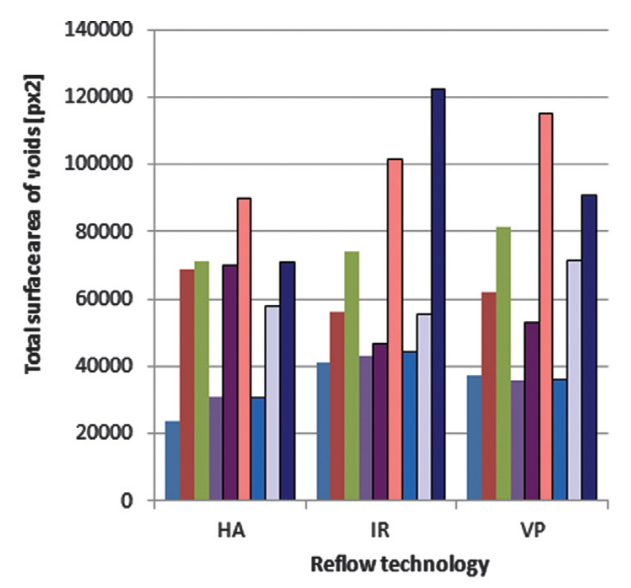

Dry-Sn62Pb36Ag2 घDry-Sn96.5Ag3Cu0.5 ㅁ Humid-Sn96.5Ag3Cu0.5

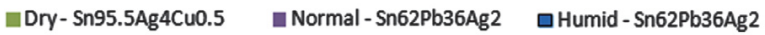

口Normal - Sn96.5Ag3Cu0.5 aNormal - Sn95.5Ag4Cu0.5 घHumid - Sn95.5Ag4Cu0.5

Fig. 10. Influence of reflow process on total surface area of voids.



Fig. 11. Influence of used solder paste on number of voids. 


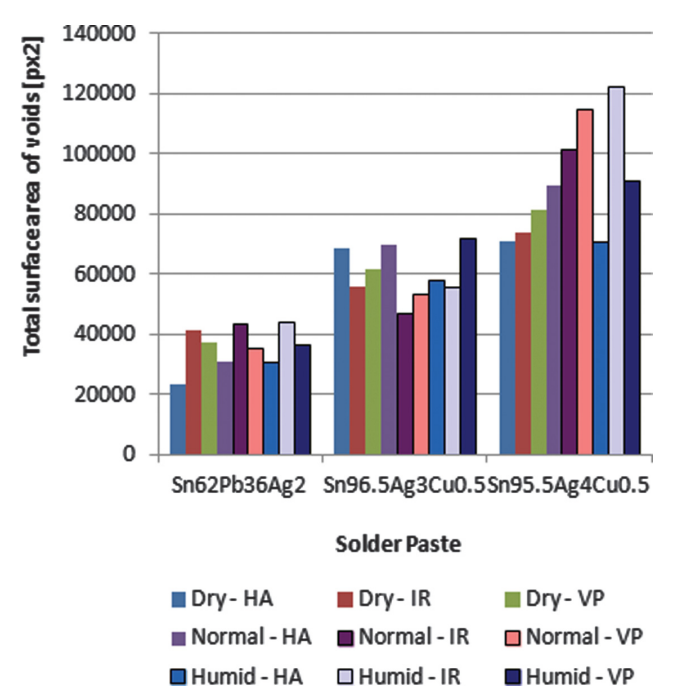

Fig. 12. Influence of used solder paste on total surface area of voids.

Influence of used solder paste on the voids formationresults are shown in Figure 11 (number of voids) and in Figure 12 (total surface area of voids). From the results one can clearly see the influence of used solder paste on the voids formation. The lowest number of the voids has $\mathrm{Sn} 96.5 \mathrm{Ag} 3 \mathrm{Cu} 0.5$ solder paste and the lowest total area of all voids has Sn62Pb36Ag2 solder paste. The worst number of voids together with total area of all voids has Sn95.5Ag4Cu0.5 solder paste.

\section{CONCLUSION}

Results indicate that the number of voids together with their total area mainly depends on type of used solder paste. Dependence of used reflow process on voids formation is minor and the influence of components humidity on voids formation wasn't observed.

Acknowledgment: This work was supported by Grant Agency of the Czech Technical University in Prague, grant No. SGS12/063/OHK3/1T/13.

\section{References and Notes}

1. M. Yunus, K. Srihari, J. M. Pitarresi, and A. Primavera, Microelectronics Reliability 43, 2077 (2003).

2. R. Aspandiar, Voids in solder joints, September 21th 2005 SMTA Northwest Chapter Meeting, http://www.smta.org/files/oregon_chapter_ presentation0905.pdf (2005).

3. D. Lang, Application Note AN9047, Assembly Guidelines for MicroFET-6 Packaging (2009).

4. Lee N. Ch and O_Hara, Voiding in BGA, Proceeding of Surface Mount International, San Jose, California (1995).

5. A. A. Primavera, R. Strum, S. Prasad, and K. Srihari, Factors that affect void formation in BGA assembly, Proceedings of the IPC/SMTA Electronics Assembly Expo, RI (1998). 